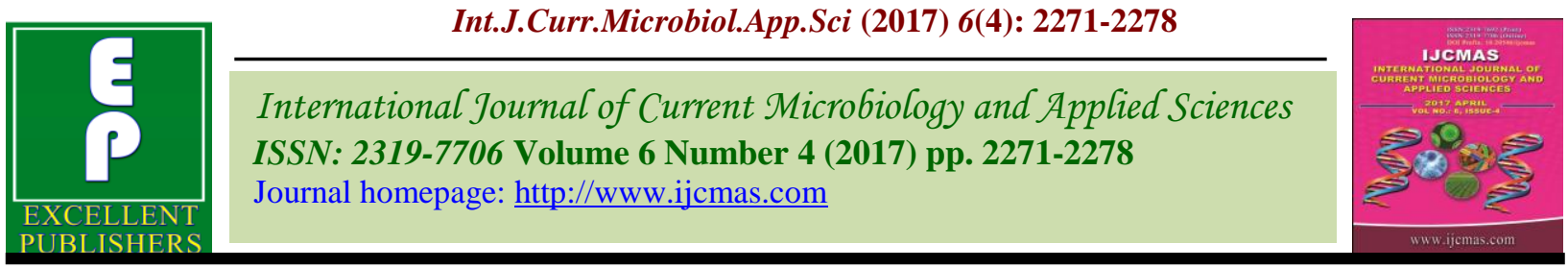

Original Research Article

https://doi.org/10.20546/ijcmas.2017.604.264

\title{
Bacterial Profile of Vaginitis
}

\author{
V. Sangamithra*, Anandeswari and Radha Madhavan \\ Department of Microbiology, SRM Medical College \& RI, Chennai, India \\ *Corresponding author
}

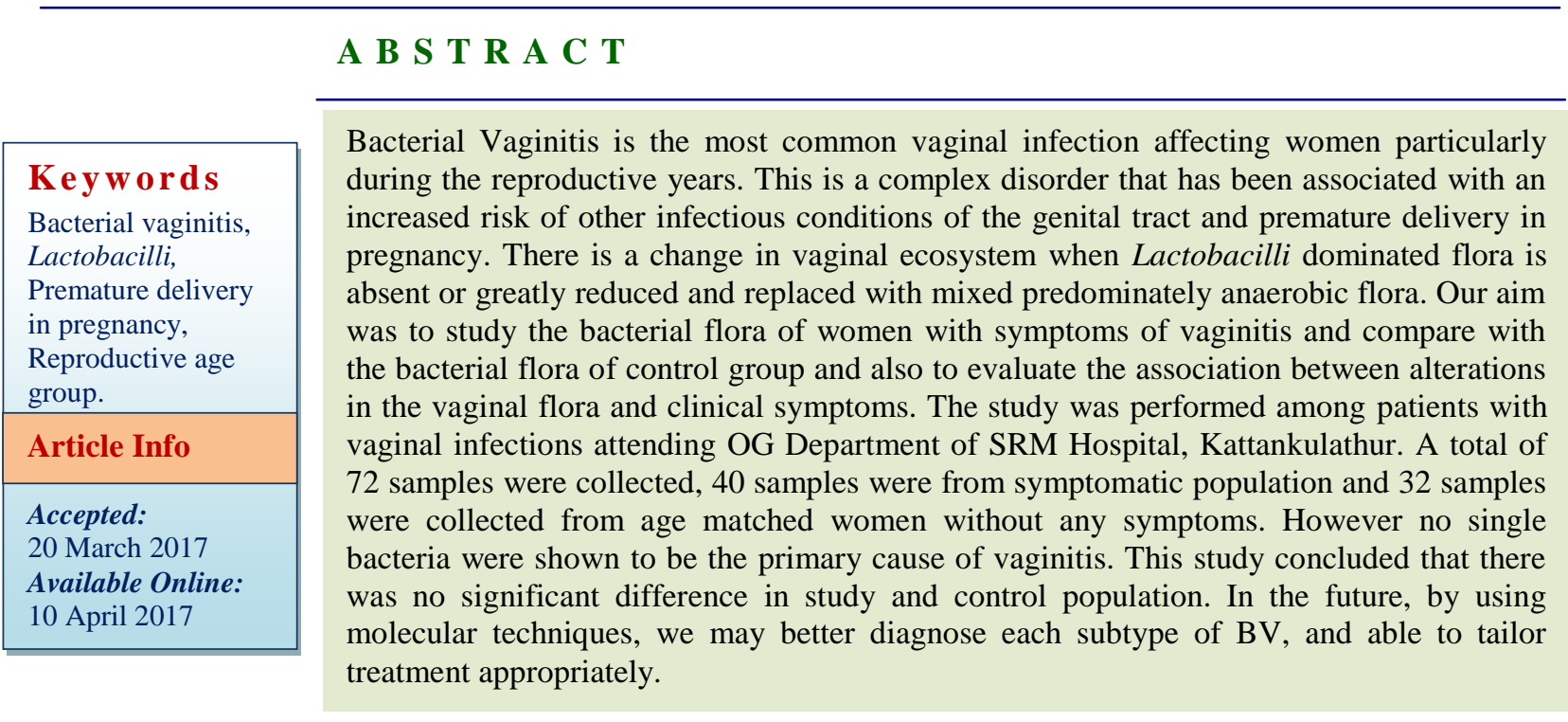

\section{Introduction}

Reproductive tract infection (Vaginitis etc) is a common public health problem with $5 \%$ of annual incidence and 40 million new infections occur every year. This problem has gained so much importance that it became part of Reproductive and Child Health $(\mathrm{RCH})$ programme which was introduced in October 1997 (American college of Obstetricians and Gynecologists, 2011; Andersonb et al., 2004; Amsel et al., 1983).

Vaginitis can be infectious or non-infectious. Infective vaginitis may be caused by bacteria, fungi, parasites and viruses. It is said that the bacteriological agents associated with vaginitis include a wide variety of bacteria that dominate by overgrowth causing deficiency of Lactobacilli which play an important role to maintain the balance of vaginal flora (Anukam et al., 2006; Brown et al., 2004; Betty et al., 2007).

Many studies have been conducted to establish the etiological role of particular bacteria which causes bacterial vaginitis (Brown et al., 2004; Betty et al., 2007). But difficulties are encountered due to many facts; difficulty in defining Bacterial vaginitis, since in some patients it can be asymptomatic; difficulty in isolation of causative organism etc. Moreover the prevalence of bacterial vaginitis also varies with population. Study of vaginal bacterial flora among women with 
symptomatic vaginitis may throw some light as to the bacterial profile in relation to the type of clinical presentation (Betty et al., 2007; Cruickshank et al., 1934; Cohressen et al., 2005).

The main aim includes to study the bacterial flora of women with symptomatic vaginitis and to compare the bacterial flora in healthy asymptomatic women, also to evaluate associations between alterations in the vaginal flora and clinical symptoms.

\section{Materials and Methods}

The study was performed during March 2011December 2011 among Patients with vaginal infections who attended OG Department of SRM Hospital, Kattankulathur. Symptomatic cases with white discharge and lower abdominal pain and other symptoms like pain, itching, burning in vagina were considered as the study population and Age matched normal females were taken as the control population. Women during menstruation were excluded from the study.

Samples were collected from posterior fornix or lateral vaginal wall of non-menstruating women with an Ayre's spatula using a nonlubricated speculum. Vaginal swabs and discharge fluid on slides were collected in duplicate.

\section{Macroscopic Examination (Odour test)}

Whiff test: The test was performed by adding a drop of $10 \%$ potassium hydroxide to the sample and a fishy smell indicated a positive test

\section{Microscopic examination}

Clue cells examination: The gram stained smear of the sample was examined for the presence of vaginal epithelial cells which were completely covered by gram variable coccobacilli so that, their edges which normally had a sharply defined cell border, were indistinct or stippled and considered as Clue cells.

Wet mount examination: One drop of distilled water was added to the vaginal discharge and screened for the presence of yeast cells and Trichomonas vaginalis.

\section{Results and Discussion}

Totally 72 samples were collected of which 40 samples represented study population from symptomatic population and 32 samples were collected from age matched women without any symptoms as control group (fig:1)

In study population, out of 51 isolates 14 were Staphylococcus aureus (27.45\%) 13 (25.5\%) were Lactobacillus species, followed by 10(19.6\%), Escherichia coli, Pseudomonas aeruginosa 6(11.8\%), Enterococci species 4 and $7.8 \%)$, Klebsiella pneumonia 3(5.9\%) and Beta Hemolytic Streptococci 1(2\%). In control population, out of 48 isolates $16(38 \%)$ were Lactobacillus spp, 11(26.2\%) were Staphylococcus aureus followed by Pseudomonas aeroginosa 6(14.2\%) Escherichia coli 5(1\%), Enterococci spp $(4.8 \%)$ and Klebsiella pneumoniae 2(4.8\%) (Fig. 2).

In study population among 40 samples 16 women had $(40 \%)$ irregular menstruation and $24(60 \%)$ of them had regular menstruation. In control population out of 32 samples 12 women $(37.5 \%)$ had irregular menstruation and 20 of them had regular menstruation (62.5\%) (Fig. 3).

None of the samples from study population grew Lactobacillus alone, whereas only one from control population grew only Lactobacillus (Fig. 4). In study population, 
out of 13 samples which grew Lactobacillus 9 samples $(69.2 \%)$ grew one isolate in addition to Lactobacillus while in control population out of 16 samples which grew Lactobacillus $13(81.2 \%)$ grew one isolate in addition to Lactobacillus. 4/13 (31\%) study population grew two isolates in addition to Lactobacilli while it was only $2 / 16$ in control population which grew two isolates in addition to Lactobacilli.

$16 / 40(40 \%)$ study population but only $8 / 32$ (25\%) control did not grow Lactobacilli from their samples. $11 / 6(68.75 \%)$ in study population and $7 / 8(87.5 \%)$ grew only one isolate; $5 / 16(31.25 \%)$ and only $1 / 8(12.5 \%)$ grew 2 isolates from study population and control population respectively (Fig. 5). On comparing the preliminary tests (Fig. 6) only $3 / 40(7.5 \%)$ samples from study population was positive for whiff test while none of the 32 control samples were whiff test positive. Clue cells were seen in 8/40 (20\%) of study population while $2 / 32(6.2 \%)$ of control population also showed clue cells. Trichomonas vaginalis was seen in 3/40 (7.5\%) study samples while none of the control samples were positive for Trichomonas vaginalis.

Two major clinical presentations were analyzed with respect to the

- Presence of clue cells

- Whiff test positivity

- Trichomonas vaginalis in wet mount and

- Bacterial isolates.

Abdominal pain was present in 9/40 (22.5\%) study population. Among this 9 patients, 2 showed clue cells (22.2\%) and GPB was present in Gram stain of 3/9(33.33\%). None of them were positive for Trichomonas vaginalis in wet mount. Staphylococci was isolated in 2/9(22.2\%) and Lactobacilli was isolated from $4 / 9(44.4 \%)$.
White discharge was the principal complaint only in $7 / 40(17.5 \%)$ patients. In direct smear, clue cells were positive in 2/7(28.5) and GPB in $1 / 7(14.2 \%)$ Trichomanas vaginalis was positive in $1 / 7(14.2 \%)$. Lactobacilli was isolated in $2 / 7(28.5 \%)$ along with 2 more isolates. Isolates other than Lactobacilli were seen in 5/7 (71.4\%). This group of patients with white discharge showed the evidence of infection, by the presence of bacteria in the absence/reduction of Lactobacilli which obviously protects the vagina from gross infection. The statistical significance could not be calculated because of the small number of patients with this complaint of white discharge among the study population.

Symptomatic patients belonged to a wide range of age from 20-60 years. There was no relationship between symptoms of bacterial vaginitis and, marital status or menstrual history.

Lactobacilli are supposed to play an important role in preventing bacterial vaginitis. Hence analysis was done to compare the isolated presence of cultivable Lactobacilli and also Lactobacilli with one or more isolate other than Lactobacilli among the study and control group. Lactobacilli with two isolates were seen in more percentage of study population $(30.8 \%)$ compared to control (12.5\%) population. But this difference was not statistically significant ( $\mathrm{P}$ value 0.3489 )

While 16 (40\%) 16/40 study population grew isolates other than Lactobacilli from their sample; only $8 / 32(25 \%)$ of control population grew isolates other than Lactobacilli from their samples. This was also not significant statistically (p value 0.3195 )

Comparison of isolates for the study and control population did not show significant difference between the two populations, though there was an apparent increase in the 
percentage of Lactobacilli isolated from control population (38\%) whereas it was only $25.5 \%$ among study population. Neither this was statistically significant ( $\mathrm{p}$ value 0.7619 )

Culture is considered to be the gold standard in any infection. But bacterial vaginosis is considered to be alteration of vaginal flora without any obvious signs of inflammantion. According to Sobel and Rao there is no single best method for the diagnosis of bacterial vaginosis. Hence this attempt of studying the vaginal flora in study and control populations was undertaken. But this study also does not throw any clear cut demarcation between the asymptomatic and symptomatic group (Cohressen et al., 2005; Collee et al., 1989; Doderlein et al., 1892).

Lamont et al., observed that normal vaginal flora is not static but undergoes shifts in their representation, abundance and virulence over time and are affected by many factors. Culture and microscopy of normal vaginal flora typically shows a predominance of Lactobacillus species, which are believed to promote a healthy vaginal milieu.

Cultivation based techniques fail to detect fastidious organisms and thus under estimate the diversity of vaginal microbial flora.

Even though molecular techniques have identified more than 120 species of Lactobacilli, healthy vaginal flora did not appear to contain big numbers of many different species of Lactobacillus but just one or two species predominantly. Racial variation, geographical area apart from food habits which influence the GI tract and hence the vagina seemed to determine the resident Lactobacillus species vagina.

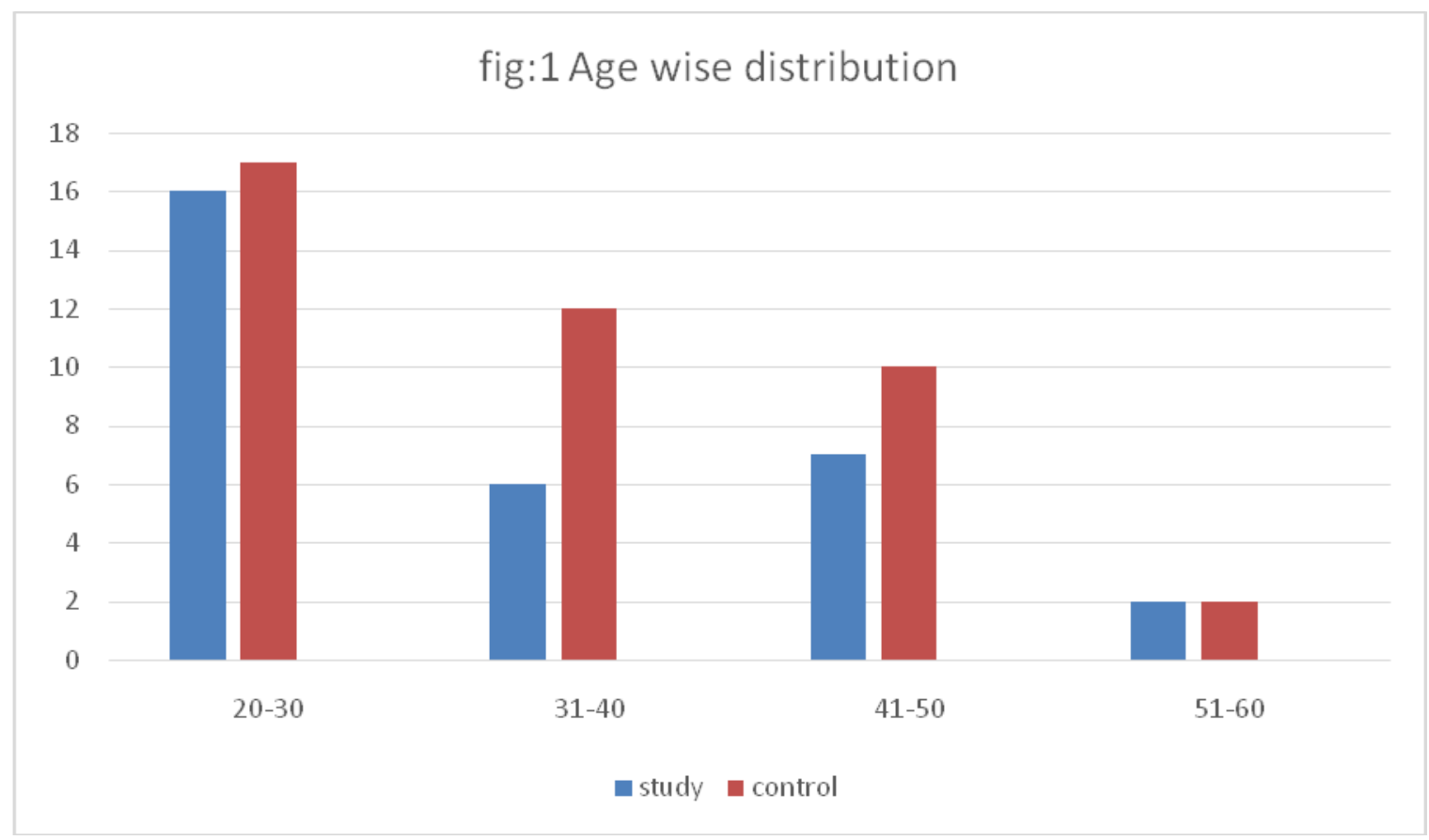


Int.J.Curr.Microbiol.App.Sci (2017) 6(4): 2271-2278
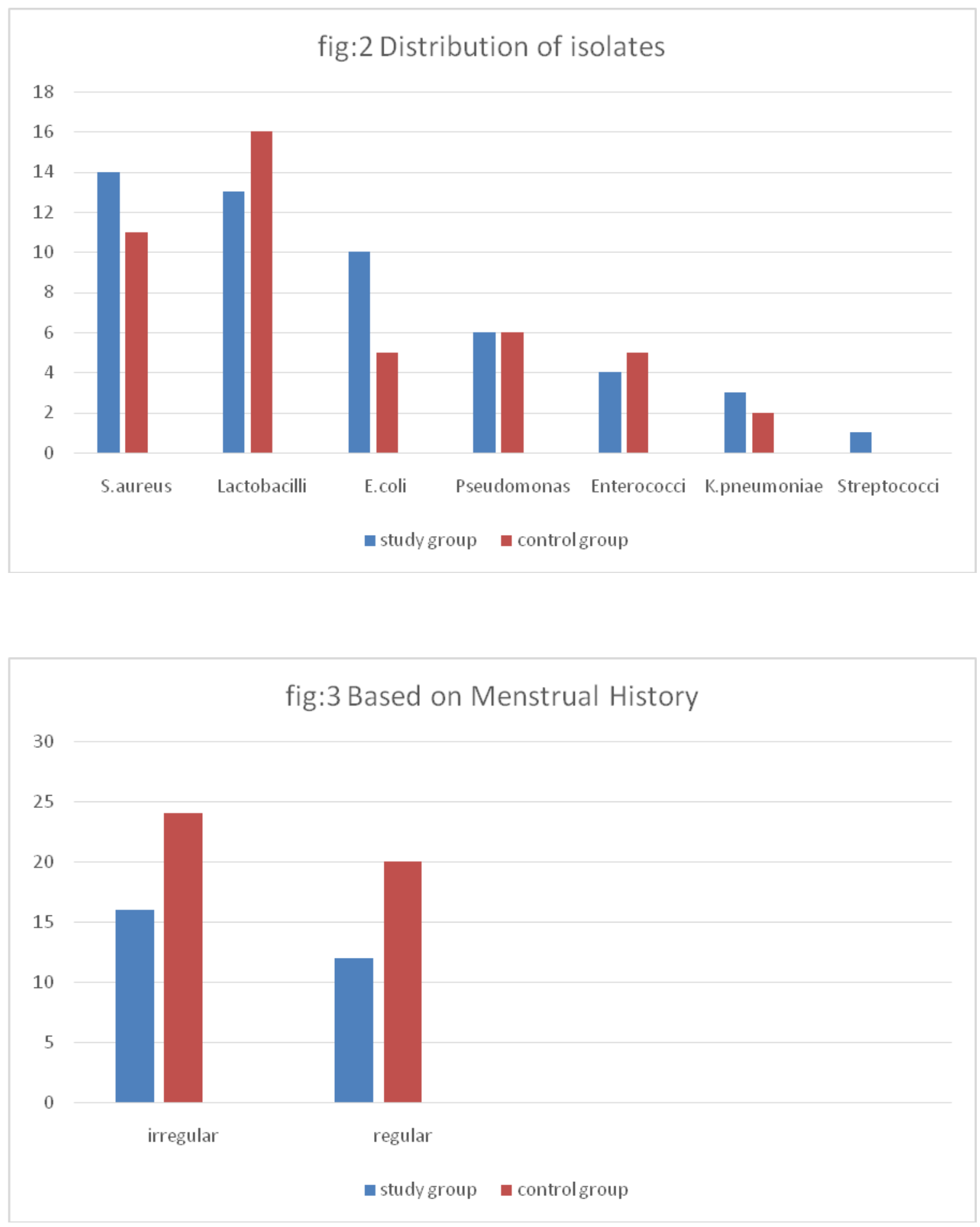

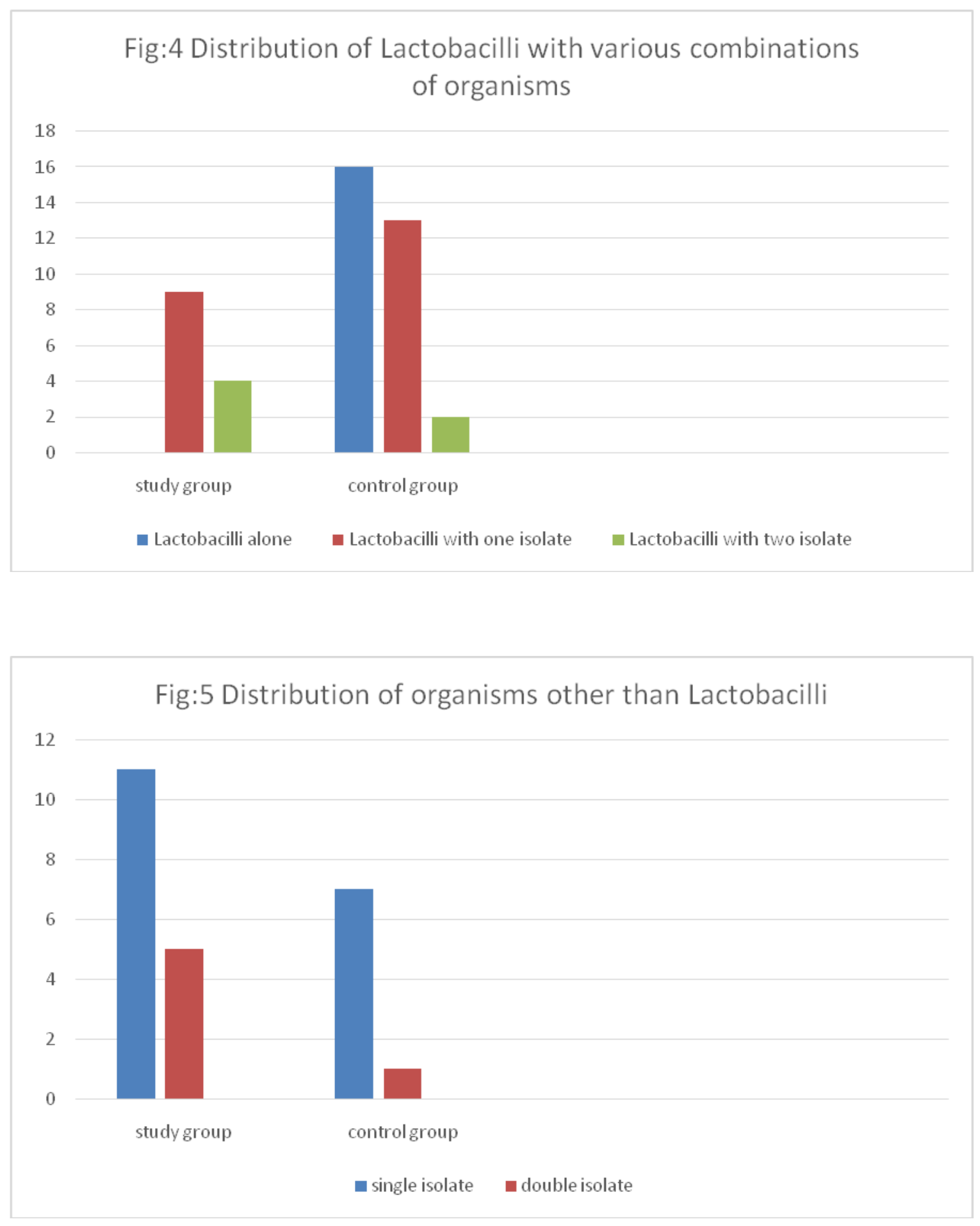


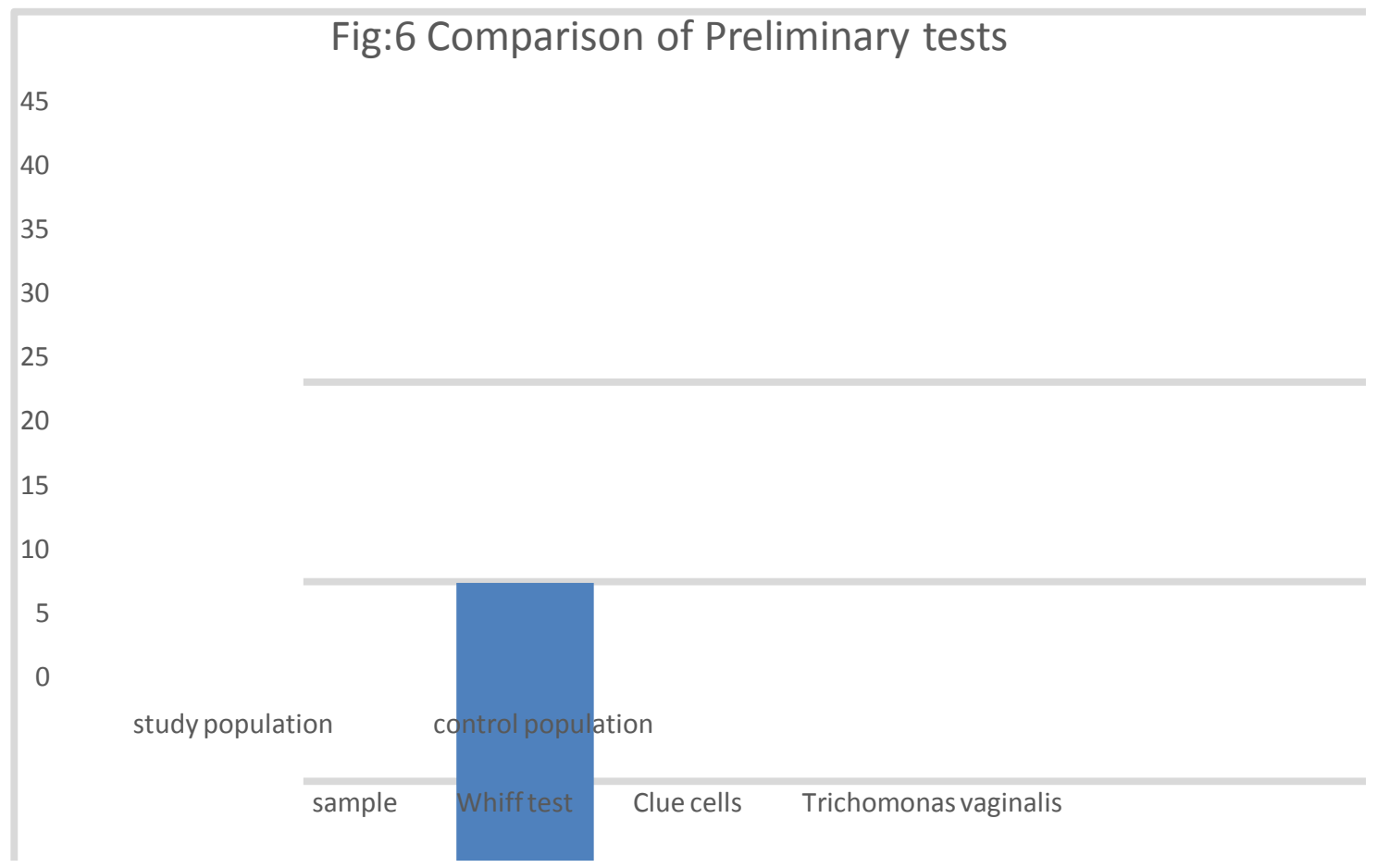

By using various molecular based techniques, Amesel's clinical criteria, or Nugent score to classify the normal or abnormal flora, a number of studies have demonstrated a high diversity of organisms in women with bacterial vaginosis compared to women with normal flora.

Molecular based techniques also indicate that bacterial vaginosis is not a single entity but a syndrome of variable composition that causes a variety of symptoms, and different phonotypical outcomes.

Molecular quantification in future may be able to subtype the BV and help to predict the outcome of appropriate therapy.

This study attempted to study the profile of vaginal flora among symptomatic women with that of age matched asymptomatic healthy women. Even though an apparent increase in the Lactobacilli was evident among asymptomatic group, the difference from symptomatic group was not statistically significant. There was no relationship between marital status and menstrual history with symptoms of bacterial vaginitis. This study also did not reveal any clear cut demarcation between the asymptomatic and symptomatic group with reference to bacteria other than Lactobacilli. No single bacteria were shown to be the primary cause of vaginitis.

Molecular techniques aimed to identify and quantify bacteria flora may throw a light into the exact etiology of bacterial vaginitis.

This study concluded that there was no significant difference in study and control population. In the future, by using molecular techniques, we may better diagnose each subtype of $\mathrm{BV}$, and able to tailor treatment appropriately. By understanding the vaginal microbial flora we can prevent sexually transmitted diseases and especially during pregnancy, we may able to predict and prevent some of the great obstetric syndromes like PPROM, Preterm labor and Preterm birth, which are associated with infection and significant infant mortality and morbidity. 


\section{References}

American college of Obstetricians and Gynecologists. 2011.

Andersonb, M.B., Klink, K., Cohrssen, A. 2004. Evaluation of vaginal complaints. JAMA, 291(11): 1368-1379.

Amsel, R., Totten, P.A., Spigel, C.A., Chen, K.C., Eschenbach, D., Holmes, K.K. 1983. Nonspecific, American J. Med., 14-22.

Anukam, K.C. 2006. Osazuwa EOAhonkai I, Reid G. Lactobacillus vaginal microbiota of women attending a reproductive health care service in Benny city, Nigeria. Sex Transm. Dis., 33: 59-62.

Brown, H.L., Fuller, D.D., Jasper, L.t., Davis, T.E., Wright, J.D. 2004. Clinical evaluation of affirm VPIII in the detection and identification of TowA, Trichomonas vaginalis, Gardnerellavaginalis, and Candida species in vaginitis/vaginosis. Infect. Dis. Obstet. Gynecol., 12(1): 17-21.

Betty, A.F., Daniel, F.S., Alice, S.W. 2007. Non branching catalase is negative, gram positive bacilli. In Bailey and Scott's Diagnostic microbiology 12 ed. Betty AF, Daniel FS, Alice SW. (eds) St. Louis, missour: Mosby Elsevier, 305-06.

Betty, A.F., Daniel, F..S, Alice, S.W. 2007. Laboratory consideration. Bailey and Scott's Diagnostic microbiology, 12 edn. Betty AF, Daniel FS, Alice SW. (eds) St. Louis, missour: Mosby Elsevier, 463-77.

Cruickshank, R., Sharman, A. 1934. The biology of vagina in the human subject, J. Objects Obstetrics Gynecol. British Common Wealth, 41: 190-207.

Cohressen, A., Anderson, M., Merrill, A., Mckee, D. 2005. Reliability of whiff test in clinical practices. J. AM. Board Fam. Pract., 18: 561-2.

Collee, J.G., Mille, R.S. 1989. Tests for identification of bacteria. In Mackie and McCartney Practical Microbiology, 13 the ed Collee JG, Fraser AG, Duguid JP, Marmion BP (eds) Edinburg: Churchill Livingstone, 141-60.

Doderlein, A., Das. 1892. Scheidensekret and seine bedeutung fur puerperalfiebr Zentabl Bakteriol Microbial hyg Abt., 11: 699 .

Doderline, A., Diescheiden sekertuntersuchungen. Zentralbatt Gyankologie, 1819: 10-14.

Eckert, L.O. 2006. Clinical practice: acute vulvovaginitis. N. Engl. J. Med., 355(12): 1244-1252.

Egan, M.E., Lipsky, M.S. 2001. Diagnosis of vaginitis. American Family Physician, 62: 1095-1104.

Eschenbacj, D.A., Gravett, M.G., Chen, K.C., Hoyme, U.B., Holmes, K.K. 1984. Bacterial vaginosis during pregnancy. An association with prematurity and Postpartum complications. Scand $J$. Urol. Nephrol. Suppl., 86: 213-22.

\section{How to cite this article:}

Sangamithra, V., Anandeswari, Radha Madhavan. 2017. Bacterial Profile of Vaginitis. Int.J.Curr.Microbiol.App.Sci. 6(4): 2271-2278. doi: https://doi.org/10.20546/ijcmas.2017.604.264 